\title{
La fruta madura \\ (el fandango sotaventino del XIX a la revolución)
}

Ricardo Pérez Montfort

CIESAS

Se recrea parte de la historia del fandango veracruzano tanto en el plano musical como en sus implicaciones sociales y culturales.

"...fandango, fruta madura, enredada al corazón, razón de la sinrazón ¿de quiénes serás criatura?..." C.R.B., 1921

L o más probable es que los fandangos ${ }^{1}$ vivieran su época de oro en el siglo pasado. Hacía poco tiempo que algún presbítero los tratara como una "desordenada diversión" del pueblo cristiano que habitaba la Nueva España, allá

${ }^{1}$ La discusión sobre el origen de la palabra fandangoes larga y barroca. Si bien con ese nombre se identifican muchas fiestas y bailes que se celebran en todo el continente americano, desde Chile hasta Cuba, de El Salvador hasta Brasil, entre los siglos xvi y xvilı se le señala una oriundez tanto

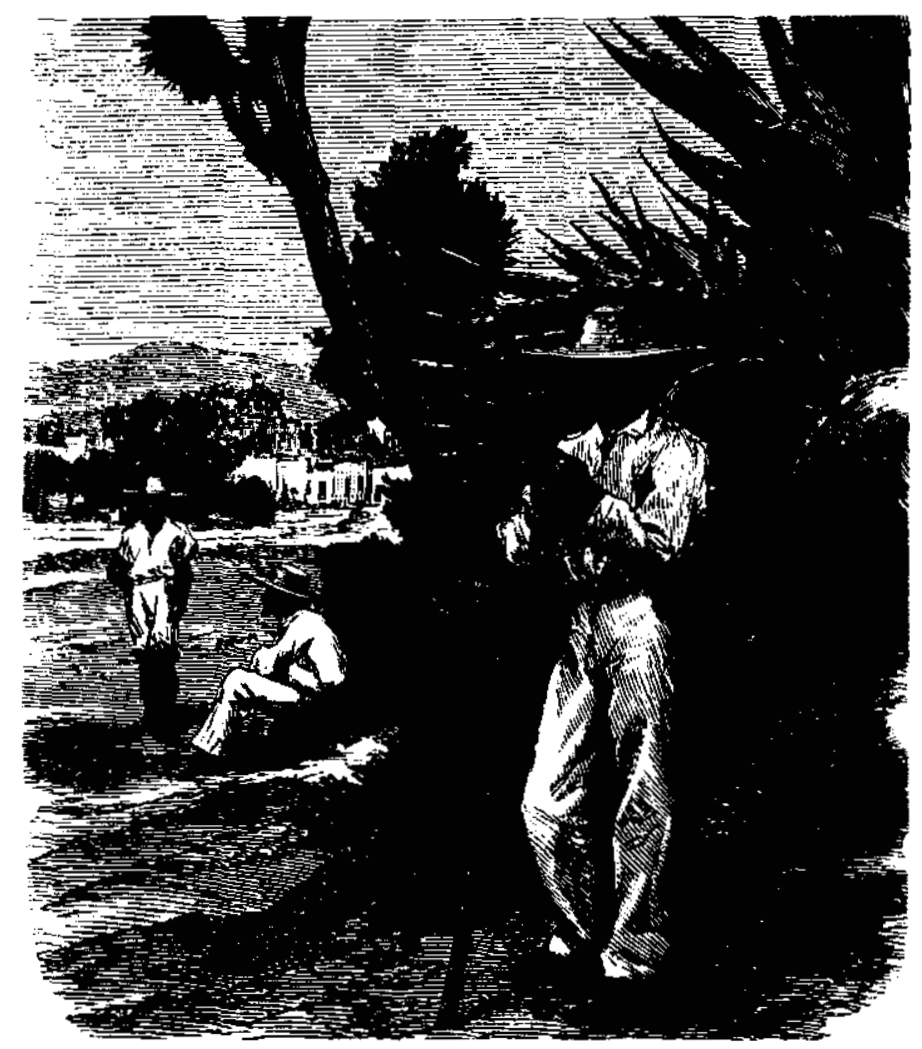


por el año de $1796 .{ }^{2}$ Combinando la fiesta con el rito, los fandangos tuvieron una existencia oscilante en los siglos XVII y XVIII. Confundidos entre "mitotes", "tocotines", "bacunaos", "guineos", "guarachas", "villancicos" "xácaras", "chaconas", "ensaladillas", "calendas" y "sarabandas" los festejos bailables de la Nueva España tuvieron un complicado desarrollo. ${ }^{3}$ No

europea como indiana. El estudioso Otto MayerSerra consigna que se trata de una "...danza de origen hispánico, muy popular en Lisboa durante el siglo xvII". Mayer-Serra, Música, 1947, p. 366. Pero el Diccionario de Autoridades afirma que "...es baile introducido en España por los que han estado en los reinos de Indias..." probablemente a fines del siglo XVII. Para aquellos que piensan que el origen de esa palabra es más bien africano o árabe, ese misma referencia afirma que "... el orden indiano del fandango, dándolo por cosa bien averiguada y cierta, parece negar la etimología árabe; y por ello alguien está inclinado a creer en una africana, con verosimilitud aceptable, aparte de que no empece el indianismo del baile al arabismo o africanismo del vocablo, por motivos fáciles de comprender en aquellos tiempos, cuando las relaciones con moriscos y guineos eran frecuentes con los españoles, y más con los del hampa, chusmas de las galeras penitenciarias. Fundanga en congo es participio de funda, que significa 'sentarse al estilo sastre', 'acusar ante un tribunal', vocablos cuya relación con el baile no acertamos a descubrir, como no sea la referente a la actitud de los espectadores sentados alrededor de los danzantes, como alrededor de los jueces y litigantes en los palavers o asambleas públicas. Más fácil es suponer una etimología mandinga de fanda, 'convite', 'dar de comer', y el despectivo ango. Recordándose la frecuente presencia de los mandingas en las Españas de los siglos XVI y XVII, esta etimología parece aceptable. Fandango equivaldría a fiesta donde se come, fiesta de convite o diversión, algo así como un té dansant de estos días que corren entre gente blanca, y de ahí al baile hubo breve paso semántico..."

Independientemente de su origen etimológico, el fandango tanto en la península ibérica como en el continente americano es referencia directa a un festejo con música y baile de tarima. Cotarelo, Colección, 1922, p. 176.

${ }^{2}$ Saldivar, Historia, 1987, p. 305.

${ }^{3}$ Moreno, Rostros, 1989, pp. 27-53. fueron pocas las ocasiones en que se les reprimió y maldijo, sin embargo ya sincretizados y sintetizados, estos festejos llegaron al siglo XIX sólidamente identificados con los quehaceres populares.

Como manifestación cultural mestiza losfandangos fueron reivindicados como las fiestas propias de los grupos que se opusieron a la continuación de la dominación española. Si bien ya formaban parte importante de las celebraciones y los ratos de solaz y esparcimiento de la población novohispana -y principalmente de la costeña-durante la cons-

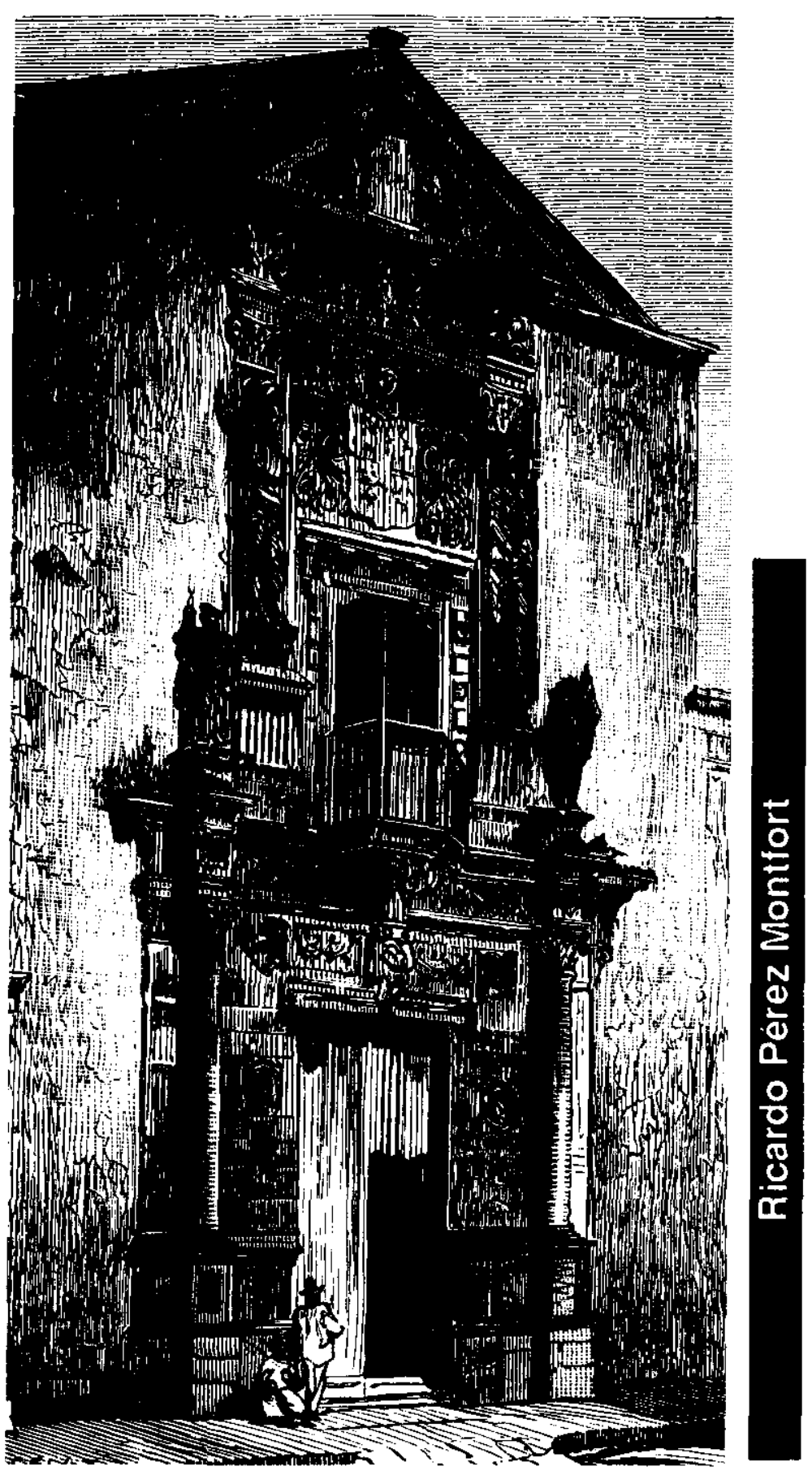


trucción del México independiente, los fandangos adquirieron, en el siglo XIX, una dimensión que confundía ciertas fibras localistas con los primeros aires nacionalistas. Por lotanto también sirvieron como afirmación de lo propio -lo mestizo o lo criollo-, frente al rechazo de lo extranjero -lo gachupín-. Su afirmación, así, no sólo cumplía con las pretensiones festivas del "pueblo" sino que le imprimía una fuerte valoración de lo "mexicano".

Aun cuando su deuda con las vertientes españolas era considerable, el fandango fue visto, y lo es hasta hoy, como una aportación mestiza a la forja de los valores locales, en oposición a la hegemonía que lograra imponer la cultura peninsular.

Por otrolado, como fiesta "del pueblo" el fandango también se propició abiertamente, dadas las intenciones reivindicativas de los anhelos populares que pretendían sustentar los hacedores de este país recién nacido. Perseguido por la intolerancia inquisitorial durante el periodo colonial, el fandango dio rienda suelta a sus anhelos y trabajos al surgir el México independiente.

La música que se tocaba en aquellas fiestas de principios del siglo XIX, ya se había calificado como "sonecitos de la tierra" a finales del siglo anterior, por lo que su identificación con los lugares, "las tierras", y con los pobladores de esas tierras, el pueblo, sirvió como argumento fuerte a la hora de reconocer "lo mexicano". Claro que cada facción, criolla o mestiza, encontraba difícil apropiarse del patronímico, cuando apenasse acababan de romper los lazos con la metrópoli europea. Además, tanto mestizos como criollos, y quizá también algunos herederos indígenas, se atribuían la capacidad de incluirse bajo el rubro de "pueblo mexicano", por lo que sus tradi- ciones y costumbres, su concepción del mundo y dela vida -con todo y sus fiestas y ritos- pretendían convertirse en visión hegemónica, a la vez que oponerse a un tributo colonial.

Con su evidente carga de nacionalismo liberal y posrevolucionario la imagen oficial nos invita a imaginar la celebración de los triunfos militares de los locales -ya fueren insurgentes 0 agustinistas- con fandangos en los que sonecitos como "Los perejiles", "La lloviznita", el "Mambrú" ola misma "Bamba" incorporaban décimas críticas y chuscas al estilo de aquéllas cuya cuarteta obligada repetía un diálogo entre el león europeo y el águila imperial del emperador Iturbide:

-Me voy, águila imperial.

- ¿Por qué causa, compañero?

- Ya reina Agustín primero.

-No tienes que hablar tú mal. ${ }^{4}$

Sin embargo lo más probable es que los pobladores delas zonas fandangueras de Veracruz no hayan vinculado tanto sus festejos a los acontecimientos de orden militar o político, tal como tampoco sucede hoy en día. Aun cuando se conserva la versada de un son tan antiguo como "El borracho", alusiva a Antonio López de Santa Anna, y se sabe de jarabitos muy frecuentes en los fandangos de antaño como "El huajito" con letra

4Mendoza, Glosas, 1957, p. 141.

${ }^{5}$ Hay una buena cantidad de coplas dedicadas a Santa Anna. He aquí algunas:

"Levántate borrachito / mira que ya amaneció / vamos a ver a su alteza / que dicen que se fugó / su alteza con el dinero / que de la patria ha robado / se ha puesto gordo y rollizo como cochino cebado/Levántate borrachito/ pues anda gente en las plazas/vamos a ver que el tirano/ nos ha dado calabazas", Campos, El folklore, 1929, p. 180.
4

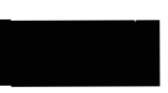


ofensiva al imperio de Maximiliano, ${ }^{6}$ seguramente los asistentes a los fandangos en aquella primera mitad del siglo XIX se preocupaban más por la fiesta en sí que por los acontecimientos del régimen y sus integrantes. Las mujeres bellas, las flores, sus animales y su entorno fueron sus temas predilectos, aunque también es cierto que de pronto aparecían las mofas a las autoridades locales o la ridiculización ocasional del gobernante.

Aun así resulta dificil suponer que aquellas coplas de corte "histórico" fueran una constante en los fandangos. Más bien eran las coplas de corte amoroso o las de tipo chusco las que predominaban. En sones como "El butaquito" o "Los enanos", reconocidos como "muy populares" en la tercera década del siglo pasado,' las coplas decían:

Y saca tu butaquito, cielito lindo, y siéntate aquí, que te quiero ver sentada toda la fiesta junto de mí.

Ay qué bonitos son los enanos, cuando los bailan primos hermanos. Son, son, son los enanos, chiquititos, veracruzanos.

${ }^{6}$ En esta época se hicieron famosas varias coplas que se burlaban de los franceses y del emperador Maximiliano. He aquí unos ejemplos: "Dizque piensan los franceses / que han venido a los infiemos/aquíno tenemos cuernos/los ponemos muchas veces// Prevengan los panderos/la danza va a seguir/ será danza de pluma / que ensaya Saligny/, Ay, ay, ay, /bueno va/ que chanza tan brutal// Ábranse las puertas/ extiéndase la mano/ que ya hay niñas muertas/ por Maximiliano", Ruiz Castañeda, "La lírica", 1972, pp. 5-50.

7 La marquesa Calderón de la Barca que escribe en 1839 menciona lo populares que eran los bailes en los que se ejecutaba el baile de "Los enanos", y "El butaquito" era conocido comouno de los sones favoritos del general Santa Anna.
Gracias a Rubén M. Campos se han podido rescatar algunas letrillas de aquella época, que al parecer servían de divertimento entre baile y baile. Aun cuando los ejemplos que rescata Campos acusan un fuerte sabor "académico", en el aire responden más a una tradición popular. Después de un remate taconeado o de una llamada para finalizar el son, que desde entonces se hacía con un "se acaba" o un "vámonos" emitido por alguno de los músicos, el versador se paraba sobre la tarima y declamaba:

En el labio de Isabel dizque una pulga picó, y luego que la pilló quitóle la vida cruel.

¡h pulga en pena tan fuerte mil veces dichosa fuiste! Bese yo donde estuviste y deme Isabel la muerte. ${ }^{8}$

Los instrumentos musicales que acompañaban al fandango eran por lo general cordófonos muy cercanos a la vihuela y a la guitarra. Se les identificaba como "jaranas", aunque se les registró con nombres muy diversos. ${ }^{9}$ Los ágiles rasgueos combinados con los no menos precisos requinteos, acompañaban a los trovadores, cuyo timbre por lo general era agudo y nasal. También era común el uso del arpa y eventualmente del violín, aunque al parecer existían toda clase de variaciones regionales que permitian

${ }^{8}$ Campos, El folklore, 1929, p. 112.

${ }^{9}$ La familia de las jaranas parece ser muy grande aunque tiende a concentrarse en cinco ramales que son, según el tamaño, de pequeña a mayor: el mosquito, la jarana segunda, el requinto o guitarra cuatro (también conocida como guitarra jabalina cuya particularidad es que se toca con un plectro formado con un cacho de cuerno de toro), la jarana tercera, y la "bocona". 
usos de otros instrumentos que iban desde el pandero hasta la marímbula.

Una de las primeras citas al fandango en tierra veracruzana durante el siglo XIX corresponde al francés Gabriel Ferry que bajo el seudónimo de Luis de Bellemare publicara sus Escenas de la vida mexicana allá por $1825 .{ }^{10}$ La fiesta a la que acude este cronista y aventurero se lleva a cabo en un lugar llamado Manantial. Con una prosa llena de acotaciones románticas el fandango descrito es el escenario de un duelo entre dos pretendientes de una muchacha de nombre Sacramento. Bellemare narra que:

...en la plaza se disponía un estrado para las [mujeres] que debían tomar parte en el baile; se animaban los puestos de agua fresca y licores, entre estos el tepache que se hace de ananás y por donde quiera se establecian mesas de juego... los hombres no bailan y son meros espectadores de las proezas coreográficas de las mujeres. Yo me situé junto al estrado que se alzaba poco del suelo y arrimado al cual estaba el tocador de guitarra. Acudieron primero ocho o diez muchachas y rompieron el baile después de dar una vuelta al estrado. Monótono el baile al principio, fue animándose poco a poco. Admiraba la agilidad y la gracia con que muchas de esas mujeres llevaban vasos de agua mientras bailaban y sin derramar una gota, o bien deshacían sin hacer uso de las manos los nudos complicados de una cinta de seda ceñida alrededor de sus pies. Este baile se llama bamba..."

Bellemare incluso consigna algunos versos interesantes que se relacionan

${ }^{11}$ Bellemare, ibid., p. 197.

${ }^{10}$ Bellemare, Escenas, 1825.
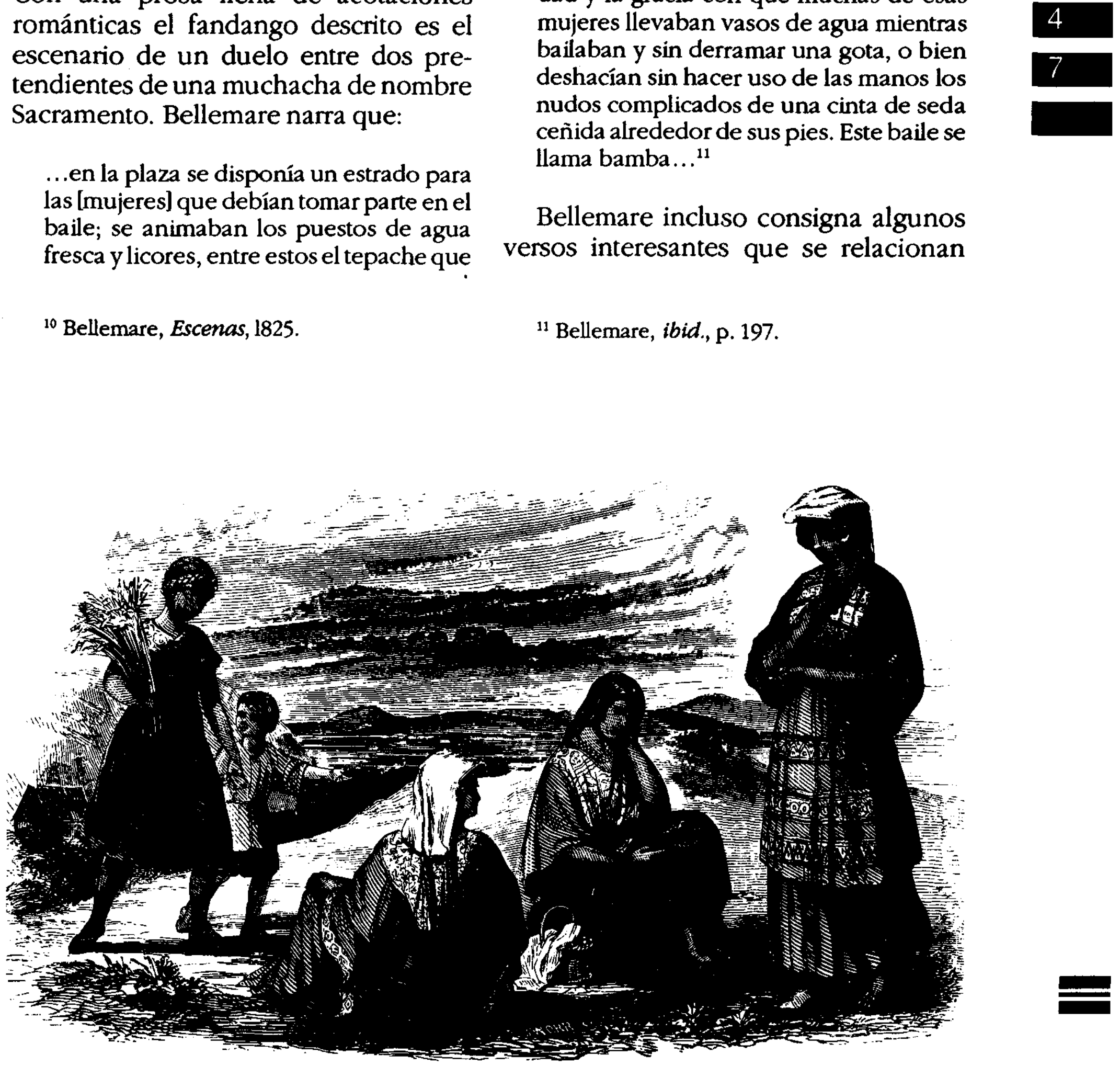
con el dueloque eventualmentedescribe. Por ejemplo uno de los contendientes se lanza a la confrontación con la siguiente cuarteta:

A ese mi competidor dile que llevo cortante, si tiene jierro y valor que se me ponga delante.

Sin embargo, algo que llama la atención es la anotación sobre el uso de las "galas" y las "bombas" que al parecer fueron herencia de diversas fiestas y bailes novohispanos. "Galear" era una tradición muy ligada al fandango que consistía en la presentación del sombrero a la bailadora predilecta quien, si aceptaba la oferta, bailaba un son completo con el sombrero puesto como muestra de buena disposición al dueño del "jarano". La "gala" se terminaba cuando la bailadora regresaba el sombrero a su dueño y éste le daba una moneda a cambio. Las "bombas", porsu parte, eran las coplas que los versadores o los mismos participantes del baile recitaban entre las diversas frases musicales del son que acompañaba al festejo. ${ }^{12}$

Otra referencia interesante a esta fiesta veracruzana de la primera mitad del siglo XIX aparece en la Revista Científica y Literaria de México publicada en 1846. En esa revista, que compartian las magnificas plumas de Manuel Payno e Ignacio Ramírez, don Alfredo Martín Vélez narró

${ }^{12}$ En algunos fandangos sotaventinos todavía es posible presenciar estas costumbres de la "gala" y las "bombas". Las "bombas" por lo general se dicen durante la ejecución del son del "Fandanguito" y suelen ser de dos tipos: para "desenojar" que son las que corresponden a las mujeres, $y$ "de hacer justicia" que son las que corresponden a los hombres. Las "bombas" también son muy comunes en las fiestas de Yucatán, y es ahí en donde se han hecho célebres. sus experiencias fandangueras en un relato que tituló "Un día en Medellín en la temporada de 183...". En este texto, el autor mostraba cómo los fandangos ya habían incorporado música de otras partes de México a su repertorio -específicamente un son llamado "El tapatío". En aquella fiesta jarocha también aparecieron ritmos y melodías de otras partes del mundo, como el minueto o la contradanza. Y a su vez también se hacía referencia a la tradición de "galear"

Después de describir su traslado del puerto de Veracruz hasta el poblado de Medellín ("aquella villa que tanto alborota al pueblo veracruzano... donde se sacrifica en los juegos de azar la fortuna de más de una familia, la reputación de más de un hombre de bien y el precio de algunas vestales ha sido rifado a todo menos el primero...") don Alfredo Martín Vélez se refiere al fandango de la siguiente manera:

“...ंQué animación! ¡Qué ruido!... Las salas de baile se forman en las garitas o corredores de las fondas, cuyo techo es de palmas: un quinqué y algunos farolillos con velas de sebo forman el alumbrado en el cuadro hay escaños para los concurrentes y en el centro una tarima sobre la que se baila y zapatea sin interupción toda la noche, cuantos sones se han conocido desde Adán hasta hoy: así se danza el minué desabrido de nuestros abuelos, como se zapatea la bamba y se cantan multitud de sonecillos alegres... muchos nuevos, importados por un anónimo compositor y otros como el ' $\mathrm{Ya}$ me enojé', el 'Churripample \& Co', con que arrullaban para dormir al padre Noé, cuando aún no había probado las uvas. Mujeres solas son las que bailan y rara vez algún arribeño (guachinango) suele atreverse a zapatear un tapatío, pero generalmente los hombres o están en el juego, o sentados sobre sus talones fuera 
del baile, o parados tras de un poste metidos en su bayeta ${ }^{a}$ acechando los movimientos de su jembra, otros se ponen junto a la música y derraman la abundancia de coplas de quevienen provistos para dar quejas a una dama o ganarse su afecto, mientras que jóvenes de otra categoría ponen sombreros y dan galas de oro y plata, resultando casi siempre que estas conquistas a pesar de la poderosa elocuencia de una onza de oro salgan fallidas para el hombre decente y ciertas para el gandul que con voz aguardentosa le ha cantado:

Te adoro con condición que van diciendo $o^{\mathrm{b}}$ mis bríos porque es mi cojtelaciónt ser cojtante en amoríos y belitred en mi pasión. Pruebas de mi amor cojtante acabo de botarte ahora, si te prefiero a mi andante ${ }^{e}$ ¿puedes pedir más, señora, a este tu rendido amante?...

"... ¿cómo dormir? cuando parecía que bajo la cama estaba el taconeo del baile y en nuestro oído el zumbido de la voz chillona de una cantadora que nos hacía escuchar sus elocuentes versos de:

2 bayeta: especie de hábito franciscano, con la entrada de la cabeza y el pecho guarnecido de botones de concha nácar, o cuartillas de plata en cantidad; manga que se usa en la costa y bajo de ella se oculta el machete.

b diciendo: yendo.

'cojtelación: costumbre.

${ }^{d}$ belitre: ardoroso.

' andante: caballo.
"Y la verdad era que la vihuela no sonaba, sino gemía bajo los poderes de dos manazas: la bulla era por todas partes como a prima noche...Los bailes siguieron hasta que la campana de la desmantelada capilla anunció que era hora de misa y por no dar escándalo paró la música..."13

Esta descripción de Vélez, además de curiosa y juguetona, mostraba cómo el fandango seguía siendo la misma combinación de sones -todos acompañados por un arpa y una "vihuela" o jarana-con la versada y el zapateado sobre la tarima. Sus reglas de corte novohispano se mantenían bastante inalteradas. $Y$ por lo visto las mujeres no sólo bailaban "de a montón" sobre la tarima sino que también participaban en el canto. ${ }^{14}$

Por su parte, el conservador veracruzano José María Esteva también consigna el canto de las mujeres. Don José María se daba tiempo para escribir sobre las fiestas locales en medio de sus varias actividades políticas. Unos cuantos años después de relatar sus observaciones sobre el fandango, Esteva abandonaría su estado natal para ocupar un escaño en el Senado, y eventualmente servir de ministro durante el imperio de Maximiliano. En 1840 registró varios sones antiguos, así como algunas coreografias intimamente ligadas al fandango:

Los sones que se bailan entre los jarochos son unos compuestos por ellos mismos, y

${ }^{13}$ Vélez, "Un día" , 1846, pp. 92-101. Las anotaciones y llamados en este texto son del mismo autor, al igual que las cursivas.

${ }^{14}$ Esta tradición prácticamente ha desaparecido. Hoy es muy difícil encontrar una cantante de sones o incluso una mujer que toque un instrumento a la hora de celebrar un fandango. Los llamados "sones de a montón", que son aquellos que sólo bailan las mujeres, siguen vigentes en los bailes de tarima del Sotavento. 
otros españoles o del interior de la república; de manera que bailan el canelo, la tusa, la guanábana, etc. lo mismoque la manola, el abualulco y el tapatio. Las jarochitas bailan con mucha gracia, y algunas veces en ciertos sones como la bamba, admira la agilidad con que taconean y hacen mil movimientos, llevando un vaso lleno de agua en la cabeza sin que se derrame una sola gota, o formando de una banda que tienden en el suelo, unos grillos que ajustan a sus pies y que desatan luego sin hacer uso ninguno de sus manos. Comúnmente, cuando empieza la música a tocar un son, se levantan de sus asientos ocho o diez bailadoras, se ponen de pie sobre un tablado elevado a algunas pulgadas del suelo, dan una vuelta y comienzan a bailar. Una de ellas (y muchas veces todas, según lo requiere el sonecito) canta contestando a los versos de alguno de los músicos y estos diálogos son las más veces graciosísimos. ${ }^{15}$

Así, a pesar de la incorporación de músicas de otros rumbos, la estructura tradicional del fandango había variado muy poco para mediados del siglo pasado. Desde épocas coloniales, el fandango surgió a partir de determinados sones interpretados con los típicos instrumentos de cuerda jarochos, la jarana, el requinto y un arpa -esa sí mucho más pequeña que la que hoy acompaña a la música jarocha- ${ }^{16}$ alrededor de un entarimado sobre el que bailaban mujeres solas y ocasionalmente parejas de

${ }^{15}$ Campos, El folklore, 1928, p. 107.

${ }^{16}$ Tomás Stanford escribió que el arpa “... en el siglo xvy, era instrumento común en las orquestas teatrales y de la iglesia del pais, en el siglo xvi se volvió característica del campesino... ", Estrada, La música , 1984, p. 26. Y en varias entrevistas realizadas recientemente con musicos veracruzanos, al igual que en fotografias de principios de siglo, se ha podido constatar que el arpa jarocha era bastante más pequeña que el arpa que hoy utilizan los conjuntos que acompañan al fandango. hombre y mujer. Entre son y son algún versador aprovechaba para declamar décimas o para decir coplas a las mujeres hermosas.

Los fandangos empezaban cuando apenas oscurecía y poco a poco la gente se iba acercando al lugar indicado con adornos de papel o con flores. Además de la clásica tarima, el espacio propicio para el fandango debía teneruna o varias candelas que iluminaran unos cuantos metros a la redonda, en donde por lo general se aposentaban los vendedores de comida y licores. La interpretación de cada son y su consiguiente zapateo podían durar mucho tiempo. Una vezseñalado el final del son, se daba un remate y la música paraba. Músicos y bailadores descansaban un momento, aunque no se desaprovechaba la ocasión para decir unos versos o para que los participantes se tomaran un trago y se pusieran de acuerdo con los demás para el siguiente zapateado.

Animado el baile a eso de la media noche o dos de la mañana, se iniciaba "la carretilla" que consistía en engarzar muchos sones entre sí para darle una larga continuidad al baile y así tratar de alcanzar la dimensión extásica y ritual del fandango, cosa que no siempre se lograba. Como fiesta popular el fandango había heredado ciertas connotaciones rituales tanto de origen prehispánico como africano. Las referencias lingüísticas, sobrenaturales y eróticas en sones como "El buscapies", "El chuchumbé" o "La lloroncita" se encontraban ya bajo la superficie de aquella celebración de corte mestizo. Sin embargo, de pronto afloraban en dimensiones extásicas, en mitos y en juegos propios de los antiguos cultivadores del son y la fiesta. ${ }^{17}$

\footnotetext{
${ }^{17}$ Moreno, Rostros, 1989, p. 38. Esta autora insiste en la creación musical novohispana como
} 
En la medida en que la "sociedad veracruzana"-aquella que nose "mezclaba" con indígenas ni con negros- fue aceptando y promoviendo el fandango, se fue diluyendo el rito y afirmando el festejo. Las coreografias vistosas como aquellas del vaso en la cabeza o la de amarrar el moño con los pies; se volvieron eventos centrales del fandango, al que de vez en cuando acudían las "gentes de bien", tal como se ha podido percibir en las referencias de Alfredo Martín Vélez y Jose Maria Esteva. El éxtasis y la dimensión iniciática del baile y la música, pasaron a las zonas secretas de la fiesta. Pudiera ser que para esas épocas tales experiencias ya hubiesen abandonado el ámbito colectivo para convertirse en un acontecer personal e íntimo. Aunque aún hoy es posible percibir los restos de aquel rito después de escuchar durante tres noches seguidas el traquetear de la tarima. ${ }^{18}$

En esa primera mitad del siglo pasado, como ya se dijo, se incorporaron muchas otras músicas al fandango. Es cierto que los sones tenían una gran deuda con la tonadilla escénica española, cuyas ricas formas musicales y repetitivos recursos literarios, fueron, a decir de Vicente T. Mendoza, la fuente principal de la "música genuinamente mexicana" ${ }^{19}$ Para principios y mediados del siglo XIX,

vínculo entre diversiones y cultos de muy diversos origenes. La vena española, sin embargo fue asimilando dichos origenes, tanto indigenas como africanos, mostrandofehacientemente su connotación dominante.

${ }^{18}$ Durante los fandangos organizados en los ranchos sotaventinos hoy en día es común la llamada "amanecida" que consiste en no abandonar la tarima hasta bien entrado el día. Llama la atención la resistencia tanto de músicos como de bailadores que son capaces de bailar y tocar hasta más de 24 horas seguidas.

${ }^{19}$ Mendoza, Panorama, 1956, p. 107. sus "ay, ay, ays", sus "carambas" y sus "cielitos" ya eran considerados como propios, frente a la demás música que provenía de Europa o de América del Norte. Pero el carácter mestizo era uno de los fundamentos del son, y éste era el núcleo musical de los fandangos.

Las otras formas musicales eran llamadas "piezas". Por lo general eran melodías valseadas y por lo tanto se permitían bailar con las parejas abrazadas. Esto no era permisible con los sones ya que zapatear y abrazarse era prácticamente imposible; además, esto hubiera propiciado que los cuerpos de los bailadores se frotaran uno contra otro, $y$ en público, cosa absolutamente contraria a la moral de la época.

Pudiera ser que esta inclusión de otras formas musicales al fandango tuviera que ver con la incorporación de nuevos pobladores -oriundos de otras localidades extranjeras o nacionales-a la fértil tierra veracruzana. Con las "piezas" también apareció el violín. Este instrumento, que hoy prácticamente ha desaparecido del son jarocho, llevaba la voz cantante a la hora de tocar aquellos valses de nueva incorporación al fandango. Las lánguidas melodías que el arpa le a compañaba, daban pie a que las parejas se tomaran de manos, cintura y hombro, y se pasearan sobre la tarima, conversando o por lo menos disfrutando del leve contacto físico. Sin embargo cuando sonaba el son, el estruendo de la tarima y el rasgueo de las jaranas orillaban al violinista a dejar la primera voz y sumarse al traqueteo. Cuando las "piezas" abandonaron la tarima para incorporarse a soirées y salones de baile, el violín se fue separando del son y del mismo fandango. Este proceso fue muy largo, ya que todavía en los años 40 de este siglo era posible encontrar grupos jarochos que no habían desechado el violín. 


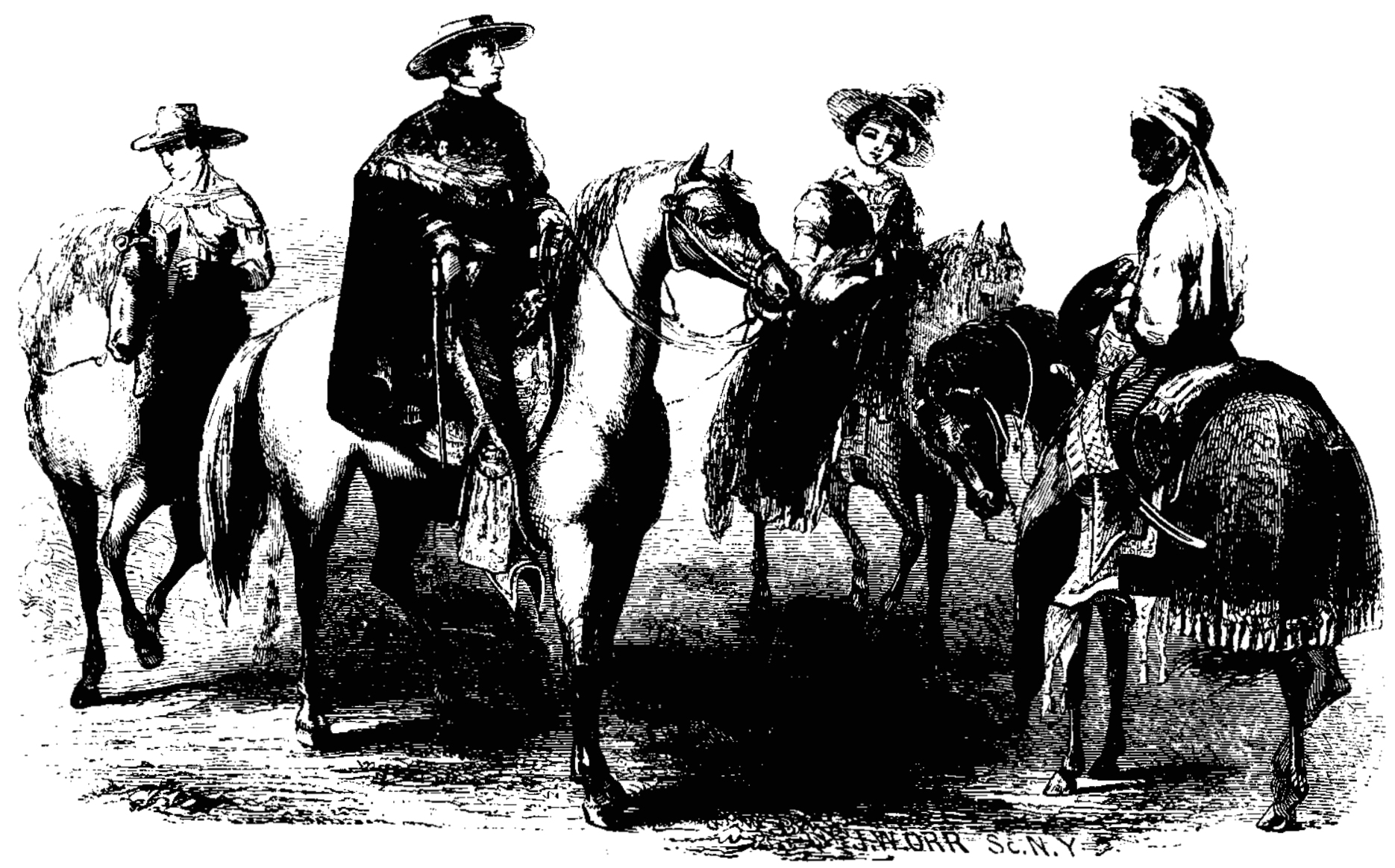

Pero volviendo al fandango, algunas de las mejores referencias en torno suyo provienen de la segunda mitad del siglo XIX, y no es de sorprender, ya que un auge económico extraordinario se experimentó en la principal zona de producción de fandangos: las tierras bajas y calientes del sotavento veracruzano. Las fiestas que presenció Lucien Biart en 1861 en las cercanías de Tlacotalpan eran muestra de aquella bonanza. Este viajero y aventurero francés que, dado su aislamiento, concebía a los jarochos como “...un pueblo aparte, con sus hábitos propios, sus leyes, sus costumbres..." noveló sus experiencias fandangueras en las márgenes del Papaloapan de la siguiente forma:

A las nueve de la noche, nos fuimos al fandango. La orquesta compuesta por dos jaranas (mandolinas) tocaba esa única y monótona música cantada por toda la gente de estas tierras. Sobre un estrado de algunos pies de largo... dos o tres bailarinas ejecutaban el baile nacional conocido por el nombre de jarabe. Sin moverse de un lugar, el cuerpo recto, giraban de una sola pieza, a veces a un lado, a veces del otro, mientras los pies marcaban la medida de un rápido zapateado. De cuando en cuando, uno de los músicos entonaba una canción, y una de la muchachas le respondía en el mismo tono. Este dúo que no tenía nada de expresivo ni de agradable, duraba por lomenos un cuarto de hora...El baile en plena calle iluminada por una linterna de papel pegada a un poste, la tez morena o negra de la gente de aquí, los abigarrados trajes, las mujeres con el torso inmóvil, agitando sus desnudos pies de modo que resonara el piso de madera: todo esto formaba un extraño cuadro de fantásticos efectos...

Por último, uno de los asistentes se levantó gravemente, puso su enorme 


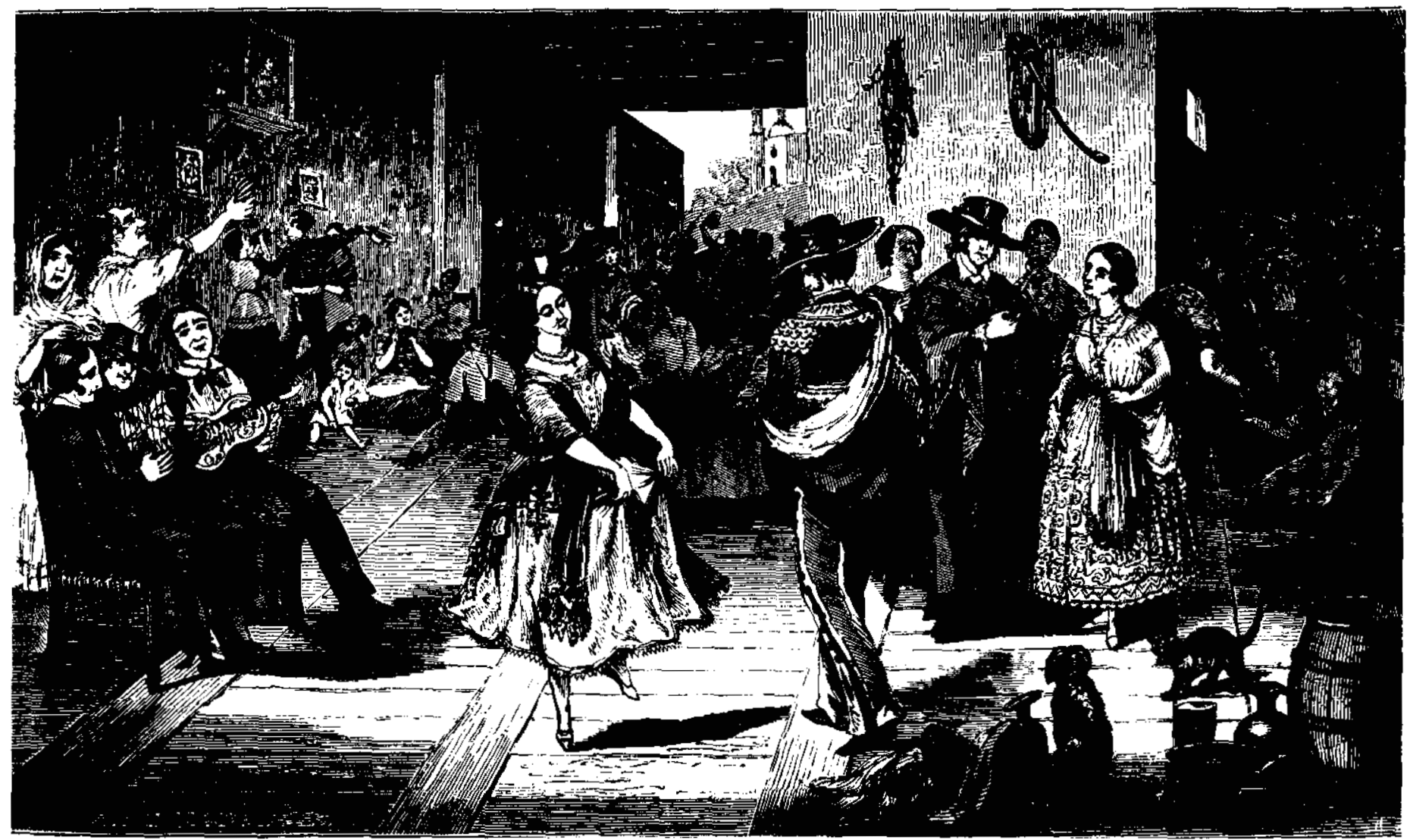

sombrero sobre la cabeza de una de las danzantes y se volvió a sentar, un segundo y un tercero hicieron lo mismo. Pronto la muchacha a la que habían escogido tuvo la cabeza cubierta por cinco o seis sombreros que mantuvo en equilibrio sin detener su zapateado. Más sombreros le fueron puestos debajo de los brazos, en las manos, entre los dientes, en cualquier parte donde se pudiera sostener; durante esta pantomima, todos conservaron una seriedad increíble. La bailarina, así sobrecargada, ejecutó un difícil zapateado, que puso el colmo a su triunfo y los músicos dejaron de tocar. Los caballeros volvieron a ponerse sus sombreros gratificando a la joven con una moneda, no como pago, sino en señal de aprobación... ${ }^{20}$

Si bien los rumbos de Tlacotalpan se mostraban prósperos hacia fines del si- glo XVIII, al parecer la piedra de toque en su auge económico fue el fraccionamiento de la hacienda El Zapotal en 1848. Pertenecientes en un inicio a la esposa de Antonio López de Santa Anna, doña María Inés García, las grandes extensiones de dicha hacienda quedaron en manos de unas cuantas familias notables de la zona. Apellidos como Alarcón, Cházaro, Carvallo, Lagos, Aguirre, Aguilera y Franyutti se afirmaron en la lista de la prosperidad tlacotalpeña, fortaleciendo a una sociedad civil cuyos vínculos se fincaron en las políticas de colonizaciôn extranjera y en el acaparamiento de actividades económicas, políticas y de "conducta moral". ${ }^{21}$

Hacia 1821, habilitado como puerto de altura en la ruta Veracruz-Nueva Or- 
leans-La Habana-Burdeos, Tlacotalpan heredó una infraestructura comercial, sólidamente fincada por la administración virreinal del Sotavento. Ahí se concentraron grandes cantidades de productos que salían de tierras sumamente ricas. Productos tan codiciados por el mercado internacional como el algodón, el tabaco, las maderas preciosas, el azúcar y las plumas de garza, pasaban por los almacenes tlacotalpeños, antes de embarcarse a lejanas tierras. ${ }^{22}$ Los ingenios y trapiches azucareros se impulsaron con maquinaria y capitales extranjeros. Además, la ganadería se expandió muchísimo, al grado que, para fin de siglo, más de $90 \%$ de las propiedades del municipio tlacotalpeño se dedicaban a la cría de toros, vacas y mulas; pero, al igual que en el resto del país, la riqueza se concentró en pocas manos. ${ }^{23}$

Aun así, la prosperidad fue el signo de la sociedad tlacotalpeña del porfiriato, tan bien descrita en los trabajos de Humberto Aguirre Tinoco. ${ }^{24}$ Por ese entonces navegaban más de diez vapores por las aguas del río Papaloapan; yuno de ellos, el Valle Nacional, además de sus enormes ruedas laterales, contaba con dos pisos y restaurante. ${ }^{25}$

¿Y cómo no iba a ser así si don Porfirio vivió en Tlacotalpan? Ahí preparó su

${ }^{22}$ Alafita, Tlacotalpan, 1989, p.41.

${ }^{23}$ Alafita, Ibid, p.44

${ }^{24} \mathrm{El}$ arquitecto Humberto Aguirre Tinoco, cronista de la ciudad de Tlacotal pan ha publicadouna buena cantidad de artículos y libros sobre su patria chica, entre los que destacan la Memoria del Museo Saluador Ferrando, 1965-76 y la Lírica festiva de Tlacotalpan de 1976. Sin sus excelentes trabajos titulados Sones de la Tierra y Cantares Jarocbos y Tenoya difícilmente tendriamos una visión completa y humana de la versada, los sones y los fandangos que se celebraron y celebran hasta hoy en Tlacotalpan, Veracruz.

${ }^{25}$ Alafita, Thacotalpan, 1989, p. 42. segunda rebelión, la que lo encumbró. Don Juan de la Luz Enríquez, un ilustre hijo de Tlacotalpan, gobernó el estado de Veracruz entre 1885 y 1892 ; y los azucareros, los ganaderos y los comerciantes de la zona hicieron su agosto beneficiados tanto por los regímenes nacionales y locales, como por la guerra de diez años que padeció la cercana isla de Cuba.

Con un crecimiento demográfico de $8.7 \%$ anual, Tlacotalpan se convirtió en un centro de actividades económicas, políticas y culturales de primer orden en el estado de Veracruz. Para 1892 no sólo contaba con el recién inaugurado Hospital de la Caridad, tenía también su muelle, su Palacio Municipal, el teatro Netzahualcóyotl, el mercado, sus academias y colegios, su biblioteca, su parroquia, su iglesia de San Miguel y, sobre todo, sus parques y plazas, sus enormes casonas coloridas y sus calles bien trazadas que servían de acceso a fábricas y casas comerciales, que eran una clara muestra de la riqueza que ahí se concentraba.

Y aquella bonanza se derramó sobre las fiestas populares. Los fandangos impresionaron a varios beneficiarios de aquel progreso. JoséAntonio Plaza, quien visitara la "perla del Papaloapan" en febrero de 1889, quedó vivamente conmovido por la fiesta. En unos versos cargados de lujuria decimonónica, el poeta observó el fandango como algo exótico y atractivo:

...Fuera del templo y llenando

de rumor la alegre plaza, el pueblo formando coro se entrega libre a la danza.

¿Quién a los bailes de sones no va a dar una mirada, donde con lascivas notas puebla el aire la guitarra? Allí no penetra nunca 
la tierna exquisita dama que en los tranquilos hogares es reina en virtud y gracia...

Llenan el baile de sones, jarochas de rompe y rasga que en la sonante tarima a vista de todos danzan.

Es la jarocha morena, con faz por el sol tostada, ojos negros y brillantes como los ojos del águila.

Con un andar muy garboso y una sonrisa muy franca, y un talle esbelto y flexible que se cimbra cuando marcha.

Tiene los negros cabellos sujetos en trenzas largas que circundan su cabeza con aire de musulmana...

Aplaude el pueblo los cantos, unos gritan,otros bailan, otros arrancan sollozos a las dolientes guitarras; y así se pasan la noche y así llega la mañana, entre risas y suspiros y confusión y algazara, mientras hermoso, imponente con su manto de esmeraldas, alegra y fecunda el río, cocos, cafetos y cañas.

¿Quién sufre terribles duelos? ¿Quién llora penas amargas?

Está en su punto la feria de la alegre Tlacotalpan: el nenúfar de las ondas, de la costa la sultana, trono de las mariposas y perla del Papaloapan. ${ }^{26}$

Una pequeña parte de esa bonanza económica también rindió frutos en

${ }^{26}$ Tomado de Aguirre, Lírica, 1979, pp. 8-9. materia educativa. Para 1872 el puerto de Tlacotalpan ya contaba con un colegio preparatoriano, además de la escuela para varones del ayuntamiento y del colegio de Santiago Moreno y Balaguer. ${ }^{27}$ En esas escuelas abundaron los maestros destacados, cosa quehizo que la preparación académica y las aficiones a la cultura fuesen una profesión que, además de dignificar la labor magisterial, permitiera tanto el ascenso social como el beneficio político.

Una ilustre figura de la educación en el estado de Veracruz, don Cayetano Rodríguez Beltrán favoreció a los amantes del fandango con una descripción que se encuentra entre los momentos más bellos de la literatura relacionada con la fiesta jarocha. Oriundo de Tlacotalpan, don Cayetano recuerda en su novela de 1919 Un ingenio el fandango "típico" de fines del siglo XIX.

Preparado el sitio a propósito para el fandango, colocaron la tarima, espaciosa y rectangular, y sobre ella fueron poniendo cajones vacíos en número suficiente para bien sustentar largas tablas en toda la extensión del cuadrilongo; de seguida estiraron una lona por medio de tensas cuerdas amarradas a las horquillas de los árboles que se erguían al pie del altozano, con la mira de servir de toldo a los bailadores; de tres en tres, a cada lado de los improvisados asientos y por la parte de afuera, se encajaron altas estacas, a manera de varales, de las que penderían los faroles... ..,Poco a poco y a prima noche, iban llegando los invitados y concurrentes; los que tomaron la delantera fueron los "vendedores" de aguardiente, licores, refrescos ygolosinas, quienes en mesas traídas para el efecto colocaban la vendeja a campo raso; después comenzaron a llegar los bailadores y sus compañeras, algunos jinetes en briosas caballerías y pocos a la

${ }^{27}$ Alafita, Thacotalpan, 1989, p. 63. 


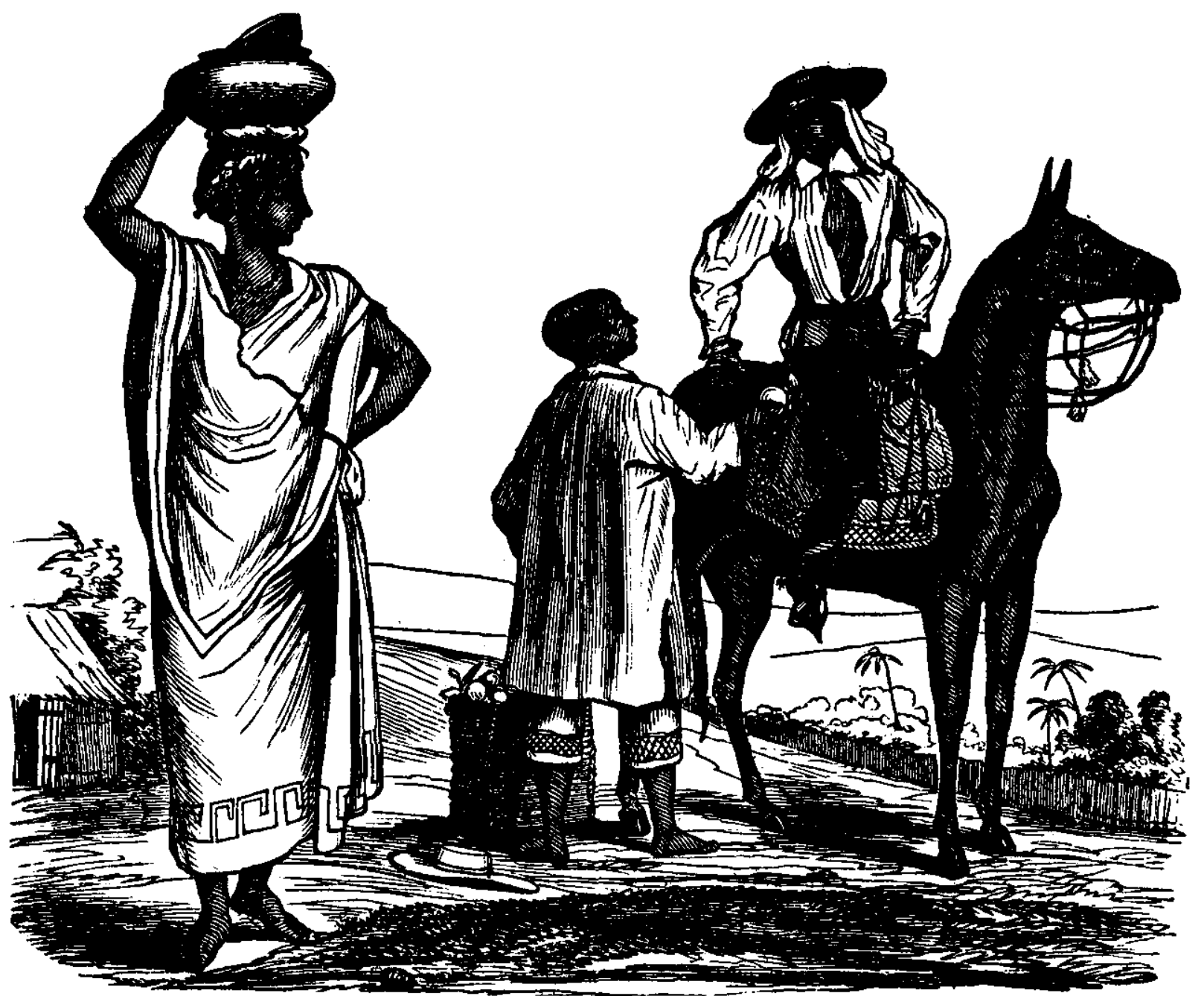

pata llana...los músicos como de costumbre llegaron los últimos...

... Cuando estuvieron juntos los músicos, que alcanzaron a cinco, se acomodaron en un ángulo de la fila de los asientos, lugar destinado para la orquesta; el del violín fue rascando las cuerdas con el arco repetidas veces sin sacar ninguna consonancia; el de la jarana probó algunos registros; el de la guitarra echó no pocos tientos; el del requinto pespunteómenudo y el del arpa tintineó fino y bordoneó hondo; con ese preludio las bailadoras tomaron sitio unas después de otras en toda la extensión de los tablones, los cantadores se encuclillaron haciendo rueda a los músicos, con los sombreros echados sobre los ojos y las manos prestas para ponerlas a guisa de bocina a ambos lados de los mofletes y aventar coplas y chillar estribillos...

...A las primeras notas...una docena de hembras, enjoyadas... se colocan en actitud de bailar, sin acompañamiento de varones, y atentas al compás de la copla que empieza:

Yo soy el pájaro Cú

que canta en la madrugada...

De seguida viene el estribillo, y a su música alegre y a su canto alharaquiento, se cruzan las parejas femeninas, zapatean fuerte, sin olvidar el acorde de la tonada que afirman en cada verso:

Y yo ya me voy

Como lo verán,

a vuelta de viaje

me la pagarán.

A poco se callan las voces, los músicos siguen tocando en seco, y las mujeres vuelven a sus asientos... ${ }^{28}$

${ }^{28}$ Rodríguez, Un ingenio, 1923, pp. 377-385. 
A lo largo de las casi 40 páginas que don Cayetano ocupa para describir el fandango, la nostalgia nos acerca a una visión muy completa de la fiesta jarocha. Aquellos tiempos idos que el autor rememora, mostraban una celebración completísima en la que no faltaban los jarabes con sus "cadenas" 29 , las "bombas para los hombres o las mujeres" y las "galas". El fandango que retrataba don Cayetano era un fandango opulento, una fiesta en donde el auge económico coloreaba a los personajes y al entorno, un acontecimiento, quizá también, magnificado por la añoranza.

Pero estas imágenes de bienestar poco tardarían en desarticularse. El oriente del presente siglo trajo consigo "...un futuro nada halagador..." para los comerciantes y ganaderos de los llanos y la tierra abajeña veracruzana. El ferrocarril transístmico, el abigeato, la imposibilidad de mantener un sistema productivo a partir de una pésima distribución de la riqueza, los pocos ricos y los muchos pobres, la inseguridad en el movimiento de mercancías provocada por algunas partidas de rebeldes unidos al movimiento revolucionario de la segunda década, los conflictos entre la capital del estado y la municipalidad tlacotalpeña, la defensa de los derechos de los trabajadores del tabaco y del azúcar, las epidemias, y muchas otras razones hicieron que la cuenca del Papaloapan perdiera su vigor económico y su proclividad hacia la fiesta. ${ }^{30}$

${ }^{29}$ Las "cadenas" son aquellas coplas larguísimas de más de 20 versos en las que los versadores engarzan sus líneas de tal manera que el último verso de una cuarteta sea el primerode la siguiente.

30 Una espléndida crónica de la revolución en Tlacotalpan es el libro Tenoya de Humberto Aguirre Tinoco, editado por la Universidad Veracruza-
Todo parece indicar que la revolución de 1910 influyó en la celebración de los fandangos en muy diversas formas. Si bien el espíritu festivo se encontraba un tanto apagado, no faltaron espléndidas figuras que hicieron del quehacer fandanguero parte de su legado para las nuevas generaciones. Es difícil pensar en una fiesta de aquellos tiempos en Alvarado, en los Tuxtlas o en la misma Tlacotalpan, sin la presencia de los versos y el buen humor de José Piedad Bejarano, el famosísimo "Vale". Este personaje que, según los decires de la zona, confrontó en el verso al impulsivo Salvador Díaz Mirón y fue poco afecto al "chaparrito Madero", ${ }^{31}$ vivió en Alvarado precisamente en aquellos años en que la cuenca del Papaloapan, y con ella el fandango, se debilitaba. Su personalidad y su gusto por la rima ágil y ocurrente lo hicieron celebridad de la zona, y aún hoy es referencia obligada a la hora de reconocer versadores sotaventinos. La mayoría de las anécdotas que de él se cuen$\tan -y$ no son pocas- suceden en los fandangos, por lo que no es dificil su-

na en 1988. Y para darse una idea del desarrollo económico y la organización de los trabajadores tlacotalpeños también es bueno el artículo de Bernardo García Díaz "Trabajadores del tabacoy la caña en Tlacotalpan" publicado en el multicitado Anuario VIdel Centro de Investigaciones Históricas de la Universidad Veracruzana.

${ }^{31}$ A José Piedad Bejarano se le atribuyen muchos versos antimaderistas. He aquí un ejemplo: "Desde que Porfirio Díaz / se fue, se acabóla paz/ reina la intranquilidad/y se cometen tropelías/De fijo se mantenía/ no quería tener cuestiones/ cobraba contribuciones/ eso todos lo sabemos/ pero hoy sólo tenemos/guerra, luto y extorsiones// De toditas estas ruinas/tiene la culpa Madero/ que se ve gente asesina/por la escasez del dinero/Pobres de los jornaleros/que es tan pocoloque ganan/Ay qué suerte tan tirana/ es preferible morir/ ya no se puede vivir / en la patria mexicana."

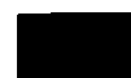


poner que éstos, aun en "la de malas", se seguían celebrando con gusto. A manera de ejemplo, se cuenta que en un encuentro de músicos, cantores y bailadores, "...un afamado trovador de fandango, del rumbo dela Mixtequilla, a quien apodaban Lunita, dijo un versito al 'Vale':

Si tu saber me entretiene, pretendo que ahora me digas

los pelos que un cuero tiene

en medio de la barriga.

"Sin pensarlo mucho, el 'Vale' se prodigó diciendo:

La pregunta que me haces

ya no me coge confuso,

mi saber se satisface

no soy de cerebro obtuso,

los pelos que un cuero tase

serán los que Dios le puso." ${ }^{132}$

Por su parte, otro personaje legendario del fandango, don Arcadio Hidalgo, recuerda que en pleno movimiento revolucionario, también se daban espacio para la jarana. " $¿ Q u i e ́ n$ iba a creer que andábamos en la bola? Ni nosotros. Después nos dimos cuenta y nos dijimos: pues ya qué, ya que nos maten. Nos fuimos al monte y ahí seguido hacíamos bulla cuando andábamos descansando con los sones." 33

Otros testimonios contemporáneos de los cultivadores del fandango también mencionan actividades fandangueras de cierta importancia durante este periodo conflictivo. Si bien los fandangos se celebraban más en las rancherías y en los poblados lejanos, en las ciudades y los puertos tampoco se desaprovechaba la oportunidad para echar un zapateado

${ }^{32}$ Hernández, Anecdotario, 1982, p. 45.

${ }^{33}$ Gutiérrez, La versada, 1985, p. 133. o un verso. ${ }^{34}$ Incluso en momentos tan aciagos como fueron los años de 1914 y 1915 , entre la intervención norteamericana y los ires y venires de los grupos revolucionarios, la vena popular siguió generando fiestas y versos. ${ }^{35} \mathrm{Sin}$ embargo, tal parece que durante el periodo revolucionario sí hubo cierta disminución de los fandangos, sobre todo en las plazas grandes.

Pasada la revolución, en cambio, el fandango tuvo una nueva oportunidad para salir a las calles y los jardines de aquellas exiguas localidades tan vapuleadas por el movimiento armado y la inestabilidad política. Durante la década de los veinte se intentó recuperar el aire festivo. El nacionalismo posrevolucionario dio bastante importancia a las tradiciones locales, tanto que las estudió y fomentó en fiestas escolares y en sus pretensiones de fomento turístico. Sin embargo algo en la base del fandango se había resquebrajado. La nueva era trajo consigo un tratamiento distinto a la fiesta. Un tratamiento que hace poco hizo escribir al decimero Mariano Martínez Franco la siguiente pregunta rimada:
Maestro arpista, usted que afina
desde el tiple hasta el bordón
y que por gran vocación
oficia en esta tarima,
quíteme un peso de encima

4 Aguirre, Tenoya, 1988.

${ }^{35}$ Humberto Aguirre Tinoco consigna una gran cantidad de versos producidos en Tlacotalpan durante aquella época. Tal vez los más representativos sean los que Rómulo Terán escribiera contra la intervención yankee diciendo: "Salid de aquí follones/y decidle al capitolio/ que mi tierra y su petróleo/ se volvió puritos nones/ que todas esas canciones/me las echo a la sotana/ y si es que la grey marrana/se obstina en intervenir/noolviden que han de salir/como bacín por ventana", Aguirre, Tenoya , 1988, p. 50. 


\section{SECUENCIA}

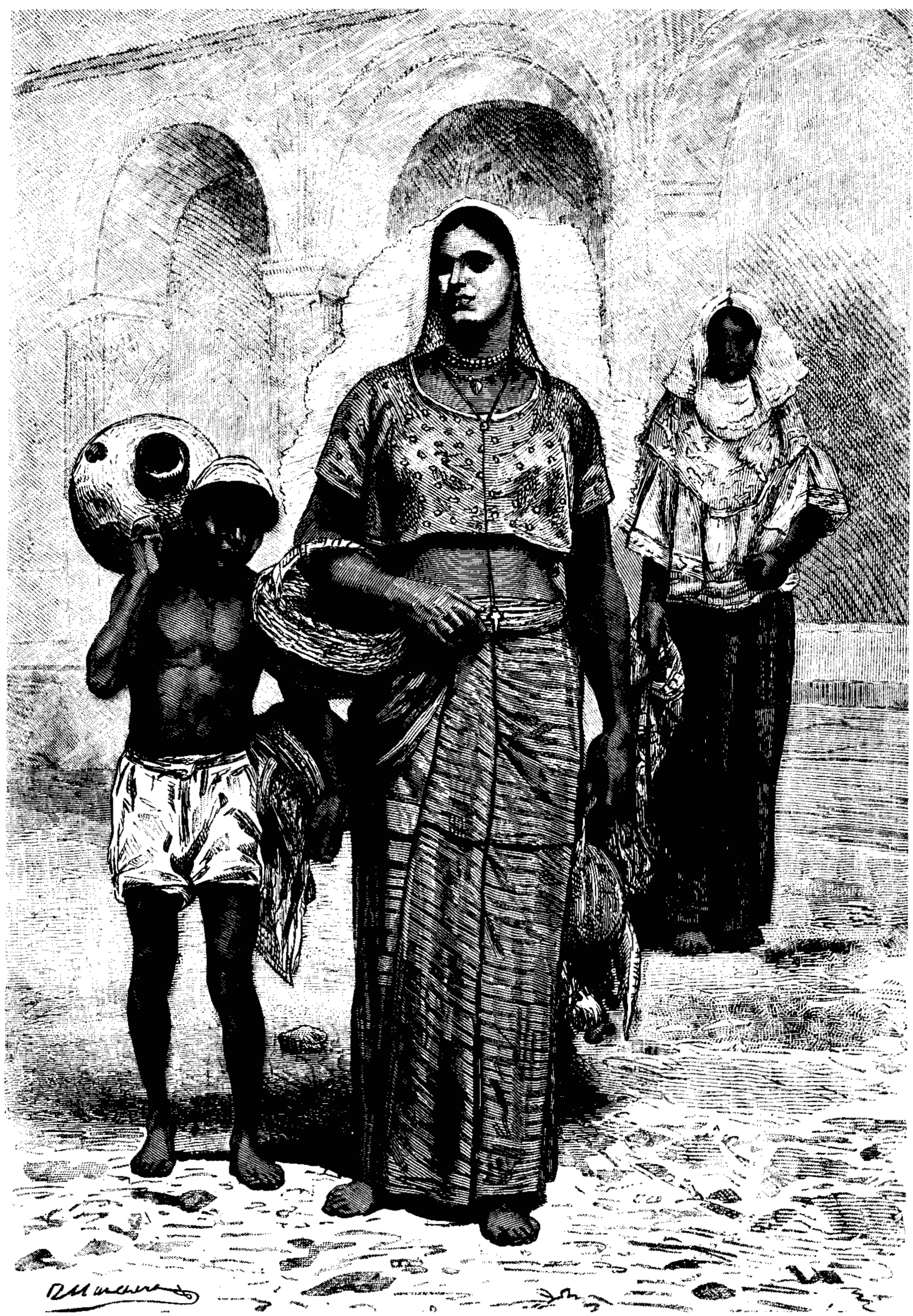


y dígame ¿qué ha pasado? ¿Por qué hemos olvidado de esta tierra el gran folclor, que brilló con esplendor y hoy ha sido desplazado?36

\section{BIBLIOGRAFIA}

-Aguirre Tinoco, Humberto, Tenoya. Crónica de la revolución en Tlacotalpan, Universidad Veracruzana, Xalapa, 1988. (comp.), Lirica festiva de Tlacotalpan, Museo Salvador Ferrando, Tlacotalpan, 1976.

-Alafita Méndez, Leopoldo, et al., "Tlacotalpan, cuando puerto fue...", Anuario VI, Centro de Investigaciones Históricas, Instituto de Investigaciones Humanísticas, Universidad Veracruzana, Xalapa, 1989.

-Bellemare, Luis de, Escenas de la vida mexicana, trad. L. García del Leal, Imp. Administración, Barcelona, s.f. (1825).

-Biart, Lucien, La tierra caliente. Escenas de la vida mexicana 1849-1862, Ed. Jus, México, 1962.

-Campos, Rubén M., El folklore y la música mexicana, SEP/Talleres Gráficos de la Nación, México, 1928.

, El folklone literario de México, SEP/Talleres Gráficos de la Nación, México, 1929.

\footnotetext{
${ }^{36}$ Martinez, Viva, 1988, p. 34.
}

-Cotarelo, Emilio, Colección de entremeses, s.e., Madrid, 1922.

-Estrada, Julio (comp.), La müsica de México I. Historia, 5. Periodo contemporáneo (1958-1980), unaM, México, 1984.

-Gutiérrez, Gilberto y Juan Pascoe, entrevista de Guillermo Ramos Arizpe, entrevista y nota de Alain Derbez, nota de Miguel Ángel Cruz, La versada de Arcadio Hidalgo, FCE, México, 1985.

-Hernández Zamudio, Alejandro, Anecdotario poético del "Vale" Bejarano, s.e., Veracruz, 1982.

-Mayer-Serra, Otto, Müsica y músicos en América Latina vol. I, Ed. Atlante, México, 1947.

-Mendoza, Vicente, T,, Glosas y décimas de México, FCE, México, 1957.

- Panorama de la música tradicional de México, Institutode Investigaciones Estéticas, UNAM, México, 1956.

-Moreno Rivas, Yolanda, Rostros del nacionalismo en la música mexicana, FCE, México, 1989.

-Rodríguez Beltrán, Cayetano, Uningenio. Enriquez Jalapa, ver Oficina Tipográfica del Gobiemo del Estado, 1923.

-Ruiz Castañeda, María del Carmen e Irene Vázquez Valle, "La musa popular en la época juarista", Revista de la Universidad de México, vol. XXVI, número 11, julio de 1972.

-Saldívar, Gabriel, Historia de la müsica en México, SEP/Ediciones Guernika, 1987.

-Vélez, Alfredo Martín, "Un dia en Medellín en la temporada de 183 ...", Revista Científica yLiteraria, t. I, s.e., México, 1846. 